\title{
Tityus serrulatus Scorpion Venom Induces Apoptosis in Cervical Cancer Cell Lines
}

\author{
Emanuelly Bernardes-Oliveira $\mathbb{D}^{\mathbb{D}},{ }^{1}$ Kleber Juvenal Silva Farias $\mathbb{D}{ }^{2}{ }^{2}$ \\ Dayanne Lopes Gomes, ${ }^{3}$ Josélio Maria Galvão de Araújo, ${ }^{4,5}$ Wilmar Dias da Silva, ${ }^{6}$ \\ Hugo Alexandre Oliveira Rocha $\left(\mathbb{D},{ }^{3}\right.$ Eduardo Antônio Donadi, \\ Matheus de Freitas Fernandes-Pedrosa, ${ }^{1,2}$ and Janaina Cristiana de Oliveira Crispim $\mathbb{D}$ 1,2,8
}

${ }^{1}$ Programa de Pós-Graduação em Desenvolvimento e Inovação Tecnológica em Medicamentos, Universidade Federal do Rio Grande do Norte, Natal, RN, Brazil

${ }^{2}$ Programa de Pós-Graduação em Ciências Farmacêuticas, Universidade Federal do Rio Grande do Norte, Natal, RN, Brazil

${ }^{3}$ Departamento de Bioquímica, Centro Biociências, Universidade Federal do Rio Grande do Norte, Natal, RN, Brazil

${ }^{4}$ Departamento de Microbiologia e Parasitologia da Universidade Federal do Rio Grande do Norte, Natal, RN, Brazil

${ }^{5}$ Laboratorio de Virologia, Instituto de Medicina Tropical, Universidade Federal do Rio Grande do Norte, RN, Brazil

${ }^{6}$ Instituto Butantan, Laboratório de Imunoquímica, São Paulo, SP, Brazil

${ }^{7}$ Faculdade de Medicina de Ribeirão Preto, Universidade de São Paulo, Ribeirão Preto, São Paulo, Brazil

${ }^{8}$ Maternidade Escola Januário Cicco (MEJC), Natal, RN, Brazil

Correspondence should be addressed to Emanuelly Bernardes-Oliveira; bio_natalrn@yahoo.com.br

Received 11 February 2019; Revised 15 April 2019; Accepted 2 June 2019; Published 23 June 2019

Academic Editor: Evan P. Cherniack

Copyright (C) 2019 Emanuelly Bernardes-Oliveira et al. This is an open access article distributed under the Creative Commons Attribution License, which permits unrestricted use, distribution, and reproduction in any medium, provided the original work is properly cited.

\begin{abstract}
Cervical cancer (CC) is classified as the fourth most common type of cancer in women worldwide and remains a serious public health problem in many underdeveloped countries. Human papillomavirus (HPV), mainly types 16 and 18, has been established as a precursory etiologic agent for this type of cancer. Several therapeutic attempts have been studied and applied, aiming at its control. However, not only do classical treatments such as chemotherapies and radiotherapies target tumor cells, but also they cause damage to several healthy cells. For these reasons, the search for new biologically active chemotherapeutic components is of great importance. In this study, we investigated the effect of Tityus serrulatus scorpion venom (TsV) on CC lines. There are very few studies exploring venom of scorpions, and, to our knowledge, no study has been conducted using the venom of the scorpion Ts V for treatment of cervical cancer lines. After challenge with TsV, the MTT assay demonstrated cytotoxic effect on HeLa line. Similarly, the cell death process in HeLa analyzed by flow cytometry suggests death via caspase, since the pan-caspase inhibitor z-VAD-fmk significantly reduced the apoptotic response to the treatment. These results suggest that venom of TsV can be a potential source for the isolation of effective antiproliferative and apoptotic molecules in the treatment of CC.
\end{abstract}

\section{Introduction}

Cervical cancer (CC) is the fourth most common female malignancy worldwide [1], responsible for $7.5 \%$ of all female cancer deaths [2]. In Brazil CC remains a major health problem and is considered the third most frequent type of cancer among Brazilian women, excluding nonmelanoma skin tumors [3]. According to the Brazilian National Cancer
Institute, there is an estimated incidence of 16.370 cases per 100,000 women for the biennium 2018-2019 [4]. Persistent infection of oncogenic human papillomavirus (HPV) is strongly associated with risk of cervical cancer and genital warts [5], with about 40 types being sexually transmitted and approximately 15 types being classified as being high risk for cervical oncogenesis $[6,7]$. Types 16 and 18 are the most 
prevalent and are responsible for $70 \%$ of cervical cancer cases [8].

Currently, treatments for this type of cancer are surgical removal via tumor radical hysterectomy [9], cisplatin-based chemotherapy sessions [2], uterine cavity brachytherapy, or intensity-modulated radiotherapy [10]. These treatments with chemotherapy and radiation can create tumor cells that become resistant [11] and the death of healthy cells which consequently leads to side effects, preventing their effectiveness [12].

Moreover, chemotherapy has been shown in some cases to have a limited effect on the cure and survival of patients, particularly in patients with cervical cancer, and especially when the disease is advanced; what is more it may promote chemoresistance or even relapse, which limits the success [1315]. Therefore, an urgent goal in medicine is the search for new biomarkers with lower cytotoxicity, with less side effects, and, at the same time, selective with normal cells, or at least presenting minimal effects $[16,17]$.

With this, one of the biggest challenges today for medicine is the search for a more effective treatment for cancer, including CC. Recently, studies have shown that venom of arthropods is a promising source in the fight against cancer $[18,19]$. Therefore, the search for new natural-born therapies has been extensively studied, from which scorpion venoms have shown much promise $[20,21]$. Previous studies, with the species Androctonus crassicauda and Leiurus quinquestriatus with their use as an antitumor agent, showed that they contributed to cell death of MDA-MB-231 (human breast cancer) and HCT- 8 (colorectal cancer) and induced reduced cell motility and colony formation correlated with the inhibitory role of scorpion venom [22]. While DiazGarcía [23] demonstrated that the crude venom of Rhopalurus junceus scorpion promoted high cytotoxicity and apoptosis via the mitochondrial line MDA-MB-231. In another study, using fractions from the venom of another scorpion species, Androctonus australis hector, it was observed that the F3 fraction of the venom presented cytotoxic action in human lung cancer cells (NCI-H358), inducing death by oxidative stress and mitochondrial dysfunction [12]. In a previous study from our group of researchers, we observed that an isolate scorpion venom of the species Tityus stigmurus, showed cytotoxicity in SiHa cells [24]. There are few studies exploring the venom of scorpions, and, to our knowledge, no study has been conducted using the venom of the scorpion T. serrulatus in cervical cancer lines. Herein, we investigated the antiproliferative effects of TsV scorpion venom in cervical cancer cells.

\section{Material and Methods}

2.1. Scorpion Venoms. The crude venom of Tityus serrulatus (TsV) was provided by Arthropods Laboratory, Institute Butantan, Brazil. The venom was obtained by electrostimulation from the method of Bucherl (1969) with slight modifications. Briefly, 15 - $20 \mathrm{~V}$ electrical stimuli were repeatedly applied to the scorpion telson and the venom drops were collected with a micropipette, and lyophilized. Stock solutions of crude venoms $(500 \mu \mathrm{g} / \mathrm{mL})$ were prepared in DMEM culture medium and filtered using a $0.22 \mu \mathrm{m}$ of millipore membrane (TPP Techno Plastic Products AG, Trasadingen, Switzerland). The use of TsV scorpion venom was developed under authorization of "Brazilian Access Authorization and Dispatch Component of Genetic Patrimony (CGEN)" (Process 010844/2013-9, 25 October 2013).

2.2. Cell Lines and Reagents. SiHa human squamous cell carcinoma HPV-16 and HeLa-18 cervical adenocarcinoma cells HPV-18-positive were donated by Dr Ana Paula Lepique (Department of Immunology, University of São Paulo, Brazil).

The cells were cultured in Dulbecco's modified Eagle's medium (DMEM, Cultilab, Campinas, SP, Brazil), supplemented with $10 \%$ fetal bovine serum (FBS, Cultilab, Campinas, SP), sodium pyruvate, and essential amino acids (SigmaAldrich, St. Louis, MO, USA), and 1\% penicillin/streptomycin solution (Life Technologies, California, EUA) at $37 \mathrm{C}, 5 \%$ $\mathrm{CO}_{2}$.

MTT 3-(4.5-dimethylthiazol-2-yl)-2-5-diphenyltetrazolium bromide and inhibitor z-VAD-fmk (carbobenzoxyvalyl-alanyl-aspartyl-[O-methyl]-fluoromethylketone) were obtained from Sigma-Aldrich (St. Louis, MO, USA), Annexin V-FITC/Propidium iodide (PI) kit Invivogen (San Diego, USA) and DMSO P.A (Dimethyl sulfoxide) came from Sigma-Aldrich, (St. Louis, MO, USA). CDDP (Cisplatin, citoplax), $50 \mathrm{mg}$, was obtained from Bergamo Taboão da Serra, SP, Brazil.

2.3. Cell Culture and MTT Colorimetric Assay. SiHa and HeLa cells were cultivated in a 96-well plate at an initial density of $5 \times 10^{3}$ cells/well and after $24 \mathrm{~h}$ were treated with $200 \mu \mathrm{L} /$ well of different concentrations of $\mathrm{TsV}$ venom $(50,125,250$, and $500 \mu \mathrm{g} / \mathrm{mL})$ and CDDP $33 \mu \mathrm{g} / \mathrm{mL}[16]$ [Cisplatin, citoplax, $50 \mathrm{mg}$ from Bergamo Taboão da Serra, SP, Brazil, drug control]. During the procedures we used as negative control (NC) cells with only culture medium. All concentrations were used in triplicate and incubated for $24 \mathrm{~h}$ and $48 \mathrm{~h}$, with the function of determining venom cytotoxicity by MTT colorimetric assay at $5 \mathrm{mg} / \mathrm{mL}(50$ $\mu \mathrm{L} /$ well) in nonsupplemented culture medium and incubated for $4 \mathrm{~h}$ at $37^{\circ} \mathrm{C}$. Then, the medium was removed and the precipitated formazan crystals were dissolved in $100 \mu \mathrm{L}$ of DMSO. After $15 \mathrm{~min}$, the MTT reduction was analysed by measuring the absorbance at $540 \mathrm{~nm}$ in a microplate reader (Biochrom ${ }^{\circledR}$ Asys Expert Plus), which was used for data analysis as described by Bernardes-Oliveira et al., 2016. The absolute value of MTT reduction was calculated as follows:

$$
\text { MTT reduction }=\frac{\text { Abs. } 540 \mathrm{~nm} \text { of sample }}{\text { Abs. } 540 \mathrm{~nm} \text { of control }}
$$

2.4. Annexin V-FITC/PI Double Staining and Analysis by Flow Cytometry and $z V A D$-fmk. Finally, to evaluate the effects of $\mathrm{TsV}$ venom on cell death of tumor cells, the SiHa and HeLa cells were cultivated in 6 -well plates $\left(2 \times 10^{5}\right.$ cells/well $)$, after treatment with $1 \mathrm{~mL} \mathrm{TsV}$ venom $250 \mu \mathrm{g} / \mathrm{mL}$ where there were no differences between the concentrations of 250 $\mu \mathrm{g} / \mathrm{mL}$ and $500 \mu \mathrm{g} / \mathrm{mL}$ of the venom when the HeLa line 


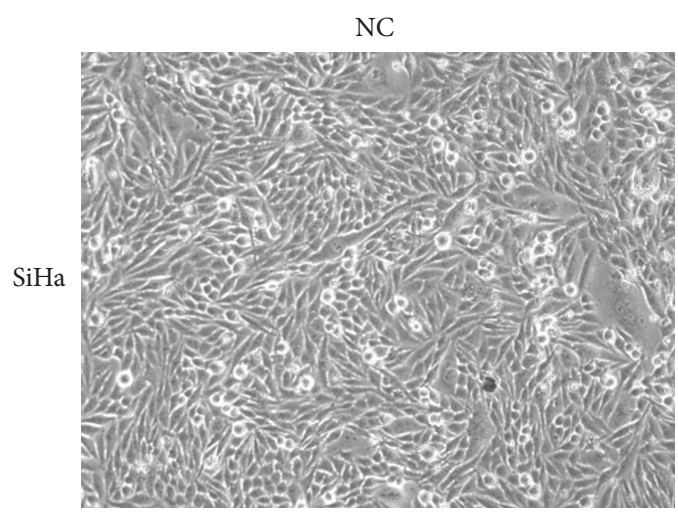

(a)

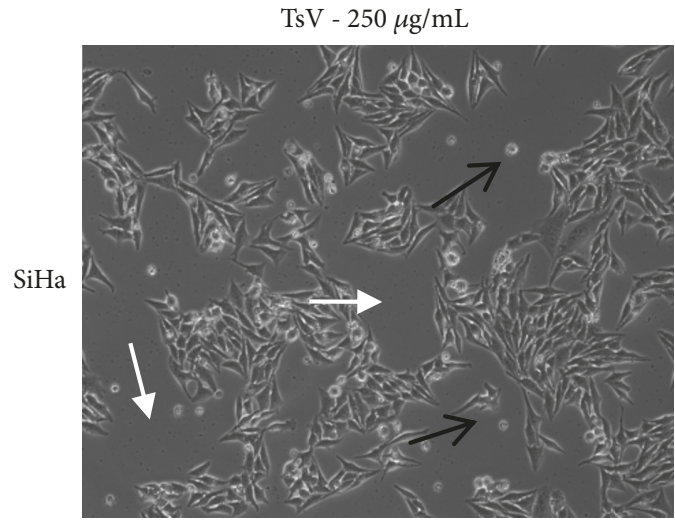

(c)

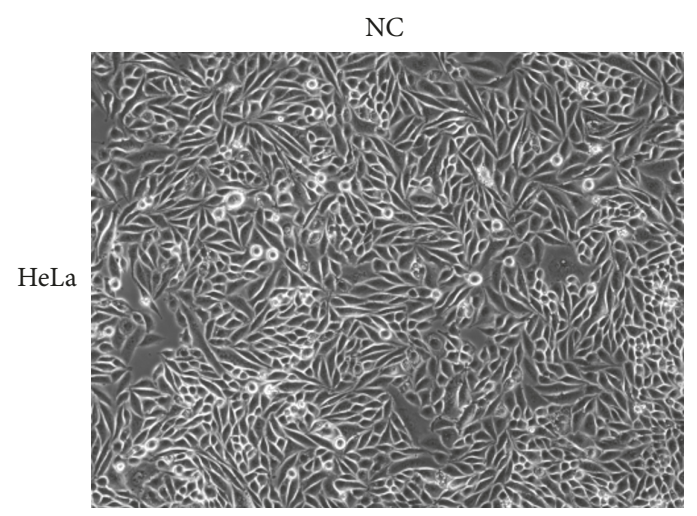

(b)

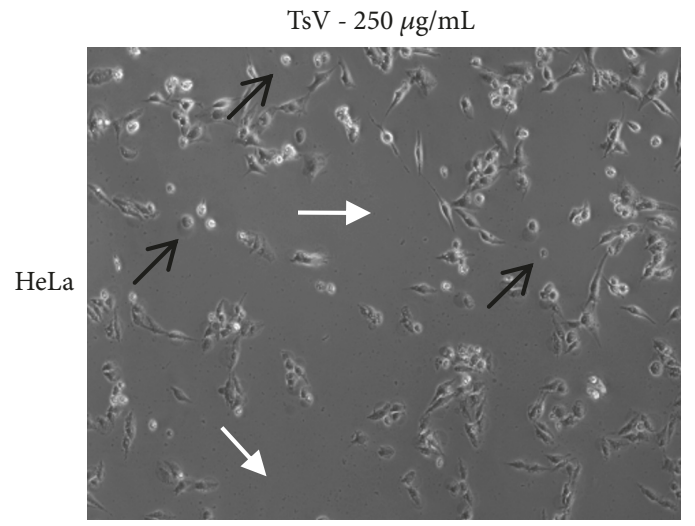

(d)

FIGURE 1: Morphological alterations of SiHa and HeLa cells induced by Tityus serrulatus venom. SiHa and HeLa cells were treated with extract $(250 \mu \mathrm{g} / \mathrm{mL})$ for $48 \mathrm{~h}$. After incubation, the cells were examined under light microscopy. The data are a representative example for duplicate tests. Magnification $\times 10$.

was treated (see Figure 2(b)). After 48 h, the medium was removed and the cells were incubated with $5 \mu \mathrm{L}$ Annexin V-FITC and $1 \mu \mathrm{L}$ Propidium Iodide (PI); then the mixture was incubated for $15 \mathrm{~min}$ in the dark at room temperature following kit directions (Invitrogen, Catalog numberV13242) as described in [25]. In the caspase activity assay, the $10 \mu \mathrm{M}$ zVAD-fmk caspase inhibitor was used in the presence of $\mathrm{Ts}$, for the other procedures the same methodology for the Annexin and PI assay of the previous experiment was used. The cells were analyzed by flow cytometry (flow cytometer FASCANTO II, BD Biosciences), measuring fluorescence emission at 530-575 $\mathrm{nm}$ for annexin $\mathrm{V}$ and $630 / 22 \mathrm{~nm}$ for PI. 10,000 events were acquired. The FlowJo software version X10.0.7 (Tree Star, Inc., Ashland, OR, USA) was used for data analysis.

2.5. Statistical Analysis. Each experiment was performed at least 3 times. We used analysis of variance (ANOVA) and Tukey's $t$-test. Differences with $p<0.001$ between the values are considered statistically significant. Statistical analysis and the Pearson correlation coefficient $(\rho)$ were performed using GraphPadInStat_software version 4.0 (GraphPad software, San Diego, CA, USA).

\section{Results}

3.1. Cell Morphology after Treatment with Scorpion Venom. $\mathrm{SiHa}$ e HeLa cells were exposed to TsV $(250 \mu \mathrm{g} / \mathrm{mL})$ for $48 \mathrm{~h}$. Subsequently, their morphology was analyzed. In Figures 1(a) and 1(b) images of the SiHa and HeLa cells (negative control) and in Figures 1(c) and 1(d) images of cells treated with the venom can be observed. The negative control cells exhibited a typical SiHa (HPV-16) or HeLa (HPV-18) cell morphology in culture, i.e., confluent monolayer with homogeneous, slightly triangular cells, normal nuclear and cytoplasmic appearance, and a few floating cells that have not adhered to the culture vessel. On the other hand, following the addition of TsV, the number of tumor cells was reduced, and the characteristic confluent monolayer was abrogated (Figures 1(c) and 1(d), white arrow), presenting cytoplasmic retraction (Figures 1(c) and $1(\mathrm{~d})$, black arrow).

3.2. Cytotoxic Effect of Tityus serrulatus Venom. The crude venom of the scorpion was used in different concentrations (see Methods) in order to analyze the TsV venom cytotoxic action on the growth of the SiHa and HeLa cervix cancer lines (Figures 2(a) and 2(b)) and 3T3. When we treated the 


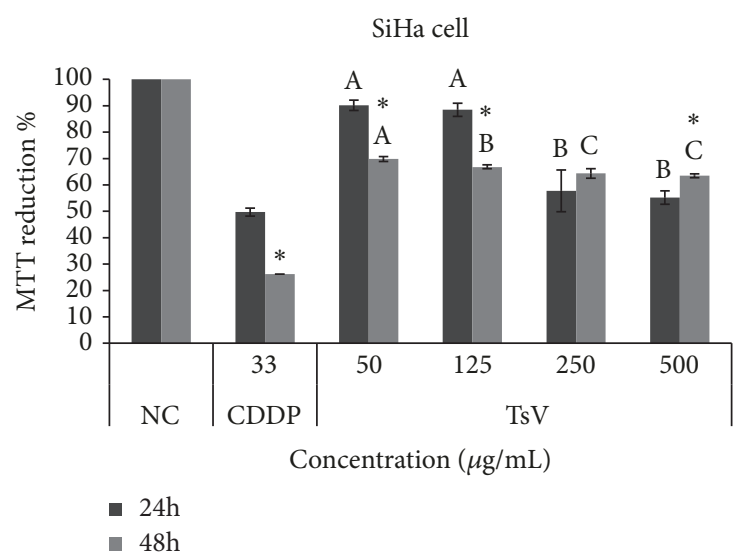

(a)

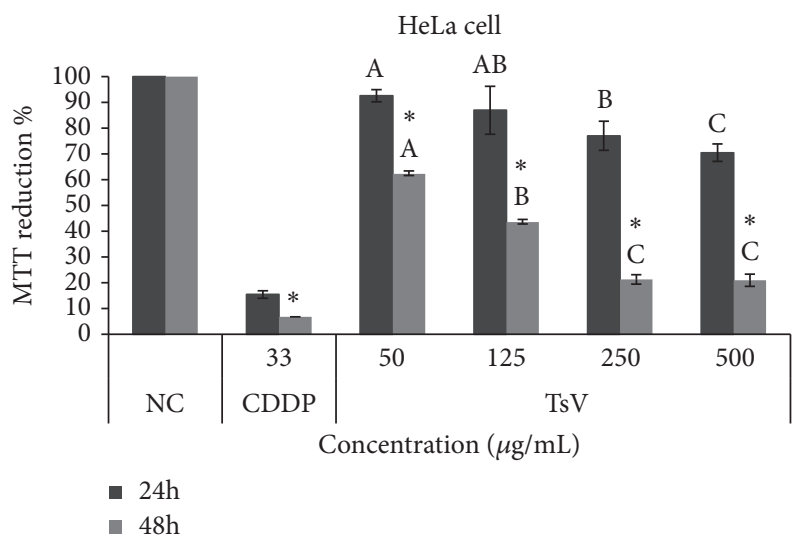

(b)

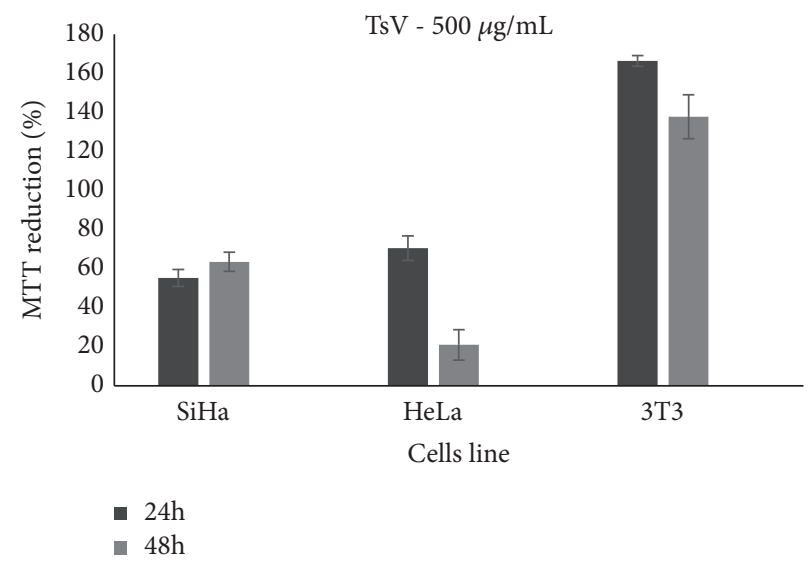

(c)

FIGURE 2: Cytotoxicity of Tityus serrulatus scorpion venom in cervical cancer lineage SiHa (a) and HeLa (b), 24h and 48h. Negative control group (NC) and T. serrulatus (TsV). Cisplatin (CDDP) was used as control drug. Different letters ${ }^{\mathrm{a} b \mathrm{~b}, \mathrm{c}}$ indicate significant differences between treatments with the same kinetics $(p<0.001),{ }^{*}$ indicates the same concentrations for different kinetics $(p<0.001) .3 \mathrm{~T} 3$ line (normal cell), treated at the highest concentration, compared to the CC lineages (c). The results were analyzed using ANOVA-Tukey test.

tumoral cell lines with $\mathrm{TsV} 250 \mu \mathrm{g} / \mathrm{mL}$ for the duration of $48 \mathrm{~h}$, the SiHa line presented cytotoxicity of $64.36 \%$ when compared to CDDP $26.23 \%$ and the NC group did not show cytotoxicity (Figure 2(a)). In relation to cytotoxicity of $\mathrm{TsV}$ in the HeLa line, a dose-dependent cytotoxic response of 78.7\% was observed compared to CDDP (93.2\%), and the NC group did not show cytotoxicity (Figure 2(b)). The same treatment in the normal 3T3 line was not cytotoxic (Figure 2(c)).

\subsection{Cytometry Analysis of SiHa and HeLa Cells after Exposure} to $T s V$ Venom. To determine the cell death pathway induced by $\mathrm{TsV}$ venom, the SiHa, HeLa, and 3T3 cells were tested for detection by Annexin and PI double staining. Generally, cells labeled with Annexin indicate initial apoptosis, cells labeled with PI are indicative of necrosis, and cells positive for Annexin and PI are indicative of late apoptosis $[16,25]$. The mechanism of cell death by apoptosis is probably the most effective action against progression of tumors and most therapeutic drugs, such as cisplatin (CDDP), which is considered the gold standard treatment, inhibiting proliferation of cancer cells via apoptosis. In order to exploit the cytotoxic effect of scorpion venom by flow cytometry, $\mathrm{Ts} V$ venom 250 $\mu \mathrm{g} / \mathrm{mL}$ concentrations were applied in SiHa and HeLa human cervical carcinoma lines and in normal 3T3 cells (Figure 3). When we evaluated apoptosis during treatment with $\mathrm{TsV}$, it was observed that the $\mathrm{SiHa}$ line presented $30.5 \%$ of apoptosis when compared to CDDP $70.2 \%$ and the NC group $0.99 \%$ (Figure 3(a)). In regard to the HeLa line, TsV induced $74.6 \%$ death by apoptosis when compared to CDDP $98.4 \%$ and NC group $0.66 \%$ (Figure $3(\mathrm{~b})$ ). To confirm the selectivity of TsV venom for only tumor cells, we used the normal 3T3 lineage, which did not present posttreatment apoptosis and showed $99.3 \%$ viability, when compared to $49.7 \%$ CDPP and $96.7 \%$ NC group.

3.4. Caspase Inhibitor Activity Assay. In view of the results analyzed in the previous experiment with the HeLa cells and to confirm whether death was via caspase, we used z-VADfmk in the presence and absence of TsV and found that there was inhibition of $z$-VAD-fmk when treated with $250 \mu \mathrm{g} / \mathrm{mL}$ of venom (Figure 4(c)). 

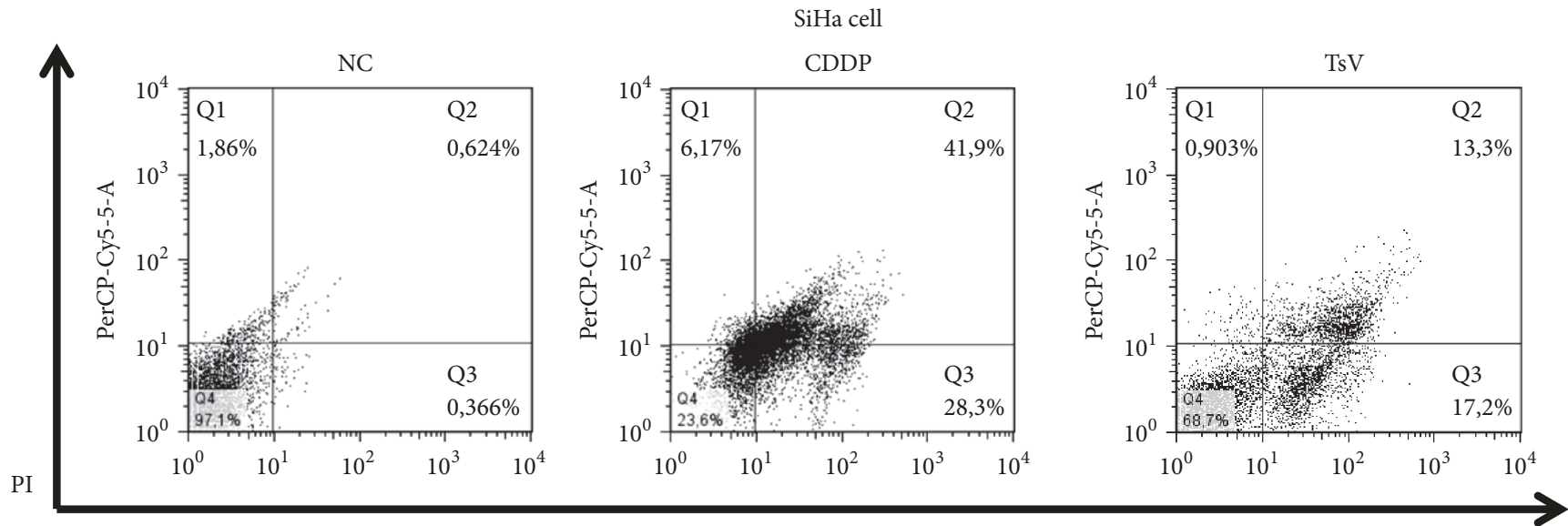

Annexin V-FITC

(a)
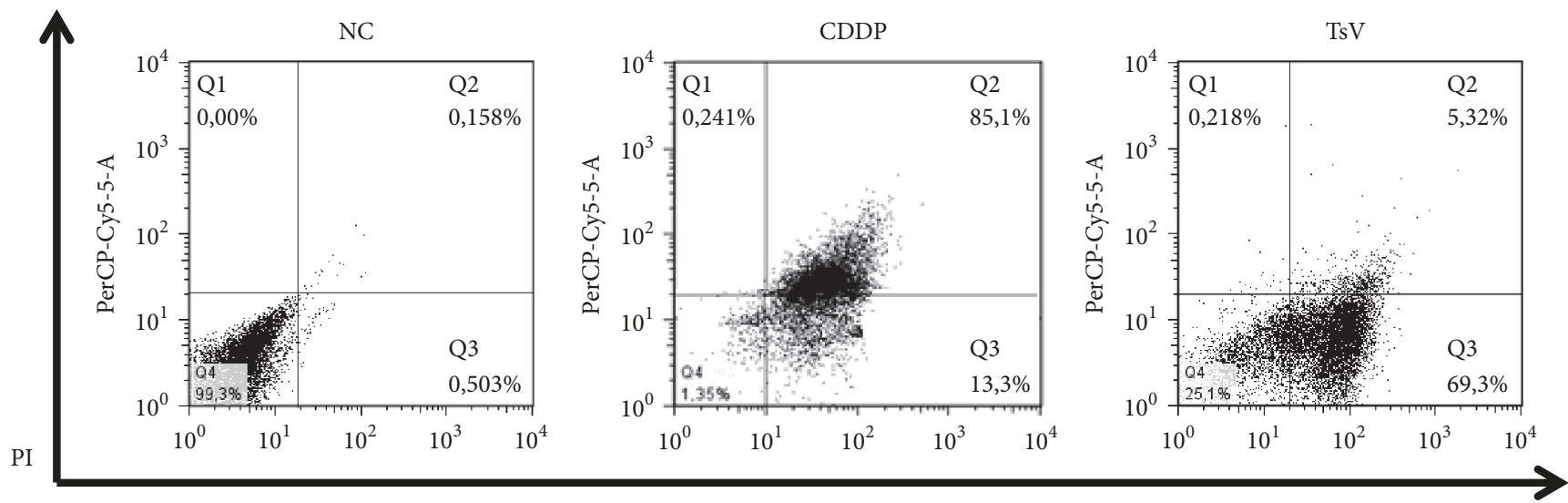

Annexin V-FITC

(b)
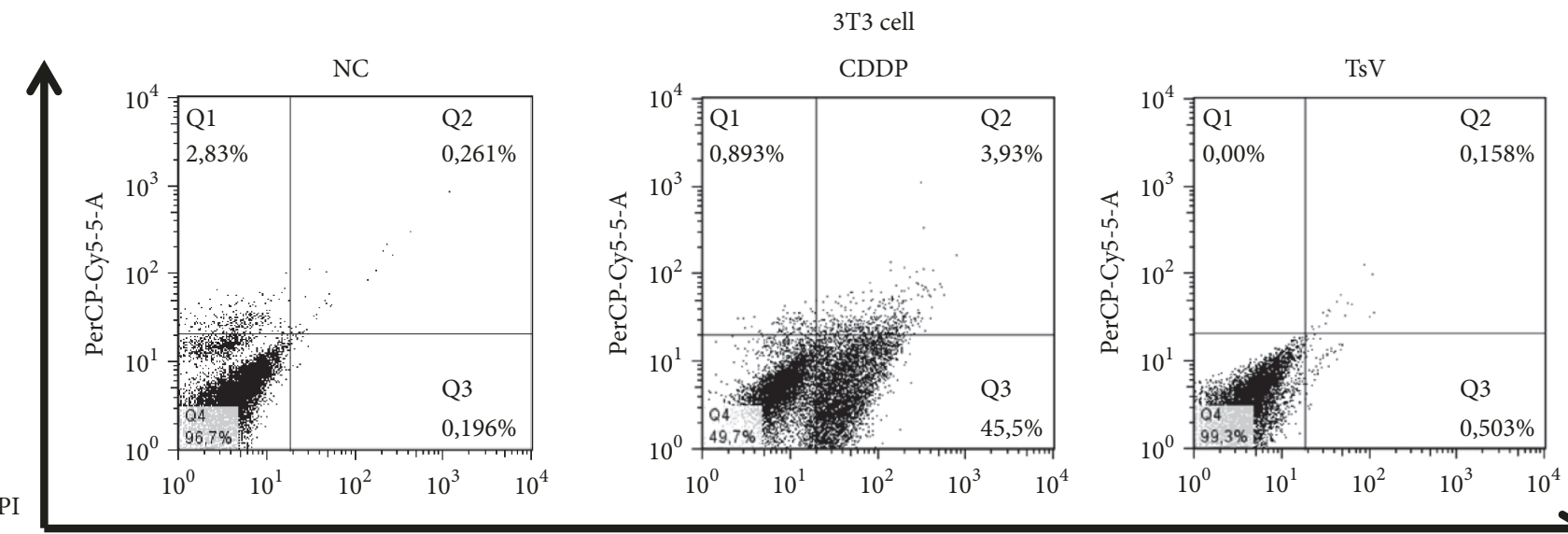

Annexin V-FITC

(c)

FIGURE 3: Flow cytometry analysis of HeLa cells after exposure to T. serrulatus scorpion venom. SiHa (a), HeLa (b), and 3T3 (c) lines, treated with $250 \mu \mathrm{g} / \mathrm{mL}$ T. serrulatus (TsV). Annexin-/PI-(Q4), viable cells; Annexin+/PI-(Q3), cells undergoing apoptosis; Annexin+/PI+(Q2), cells that are in end-stage apoptosis or are already dead; Annexin-/PI+(Q1), cells that are in necrosis. 


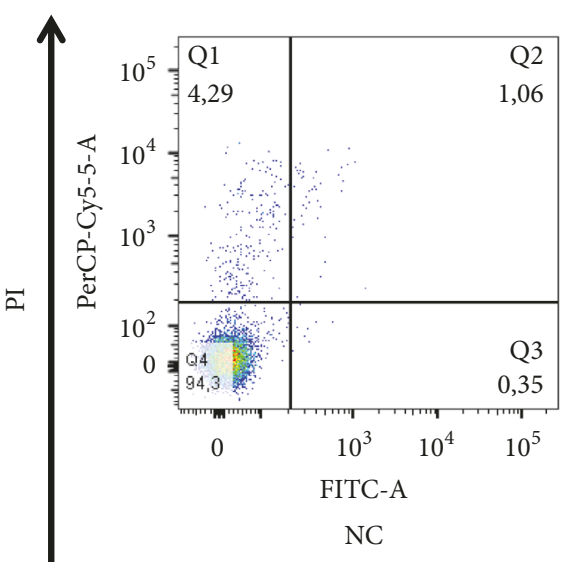

(a)

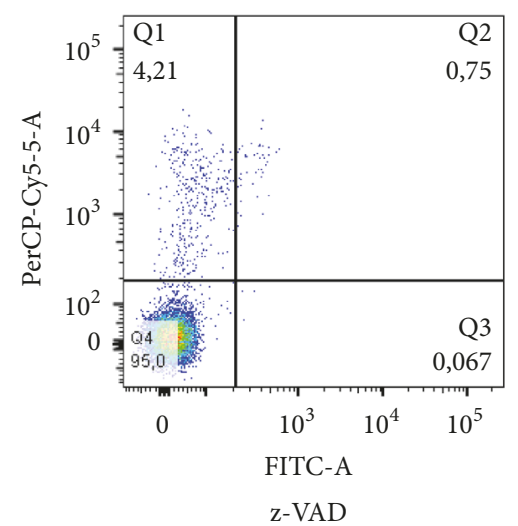

Annexin V -FITC

(b)

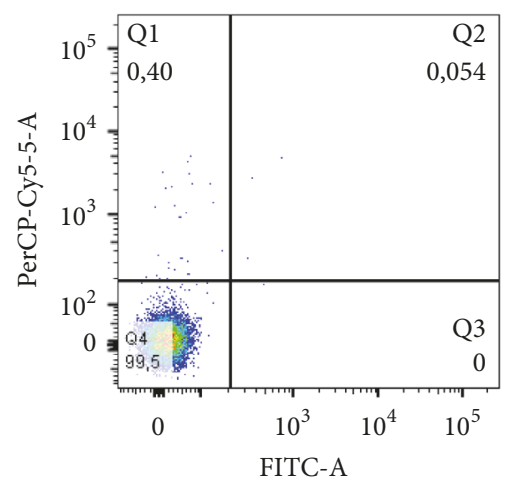

$250 \mu \mathrm{g} / \mathrm{mL} \mathrm{TsV}+\mathrm{z}-\mathrm{VAD}$

Figure 4: Apoptosis assay HeLa cells after exposure to TsV and $z$-VAD-fmk. HeLa cells treated with 250 $\mu g / m L ~ T s V$ with the caspase inhibitor. Annexin-/PI-(Q4), viable cells; Annexin+/PI-(Q3), cells undergoing apoptosis; Annexin+/PI+(Q2), cells that are in end-stage apoptosis or are already dead; Annexin-/PI+(Q1), cells that are in necrosis.

\section{Discussion}

The high incidence of cervical cancer affects women all over the world. What is more, mortality from this type of cancer has gradually increased in various countries. The discovery of molecular signatures in cancer, with the potential for future biomarker development to identify individuals who are at high risk of cancer, is still needed in clinical practice. Further studies are warranted to evaluate different approaches and explore the predictive potential, especially in the detection of individuals who are vulnerable to progression of intraepithelial lesions and cervical cancer. In general, many of the commonly used serum tumor biomarkers are limited to late-stage disease and have low sensitivity and specificity. It is known that chemotherapy is a common therapeutic intervention for different types of cancer [26], including cervical cancer, and is used as primary or adjuvant therapy.

However, these types of chemotherapeutic interventions can cause several side effects to the patient, promote resistance to the tumor, and are not selective, causing damage to normal cells [27].

That is why using scorpion venom as a source represents an interesting biological treatment for cancer ([28]; Giovannini et al., 2017). Herein, we investigated the antiproliferative effects of $\mathrm{Ts} V$, and the treatment with these venoms resulted in a dose-dependent decrease in HeLa cell viability. The same was not observed in the SiHa cells, demonstrating a lower sensitivity. Studies by Machado et al. (2017) found that the multifunctional antimicrobial peptide of the T. stigmurus scorpion (TistH) has a cytotoxic action for SiHa cells; the same was not found when normal 3T3 cells were challenged under the same conditions.

In view of these findings, the TsV venom in HeLa cells is classified as a pioneer, even in other tumor strains. Recently Luo et al. [29] demonstrated that about $60-70 \%$ of this tumor lineage was resistant to chemotherapy with cisplatin when compared to the sensitivity of HeLa and C33A cells. Evidence emerging from this study has shown that $78 \mathrm{kDa}$ glucose-regulated protein (GRP78) may be the inducer of chemoresistance in $\mathrm{SiHa}$ and to strengthen this break in resistance, it suggests the silencing of GRP78 which plays a significant role in the progress of oncogenesis. This approach can hypothesize that this susceptibility differential may be related to the expression of the HeLa cell, recognized by the $\mathrm{TsV}$ venom. Indeed, as seen by Contreras-Ortiz and colleagues [30], venom of the scorpion Centruroides limpidus limpidus was not cytotoxic to HeLa cell cultures, suggesting that this may be partially attributable to the absence of specific cell membrane targets for molecules present in the venom.

One of the mechanisms of death induced by scorpion venoms is via caspases, the beneficial pathways in cancer therapy, as seen in our results, corroborating with the studies of other researchers who challenged different tumor cell lines, including leukemic cells when treated with the venom of the scorpion Heterometrus bengalensis Koch [31], cervical cancer cells (Rhopalurus junceus) [28], and prostate cancer cells (Androctonus amoreuxi) (Akef et al. 2017). These results were also seen by Al-Asmari et al. [32], where venoms of the scorpions Androctonus crassicauda, Androctonus bicolor, and Leiurus quinquestriatus also induced a death via apoptosis. Therefore, based on these findings and other published studies, a conclusion can be drawn that scorpion venom possesses cytotoxic and apoptotic properties against cervical cancer cell lines. This type of death was confirmed when the pan-caspase inhibitor (zVAD-fmk) was activated, in the presence of $\mathrm{TsV}$ venom, suggesting that the venom of this species of scorpion may be a strong candidate for antitumor treatment. To our knowledge, no approaches demonstrate that $T$. serrulatus scorpion venom possesses cytotoxic properties against cervical cancer cell lines. 


\section{Conclusions}

Studies with scorpion venom have contributed significantly to the development of new biomedical research. Various bioactive molecules can be found in these venoms, which may present significant pharmacological activity in human physiology. More research is needed to better understand the cytotoxic action of Tityus serrulatus venom. Therefore, we suggest studying more deeply the mechanisms involved in cell death. So far the results are promising for its application in cervical cancer therapy.

\section{Data Availability}

The data used to support the findings of this study are available from the corresponding author upon request.

\section{Conflicts of Interest}

The authors declare that they have no competing interests.

\section{Authors' Contributions}

Emanuelly Bernardes-Oliveira, Kleber Juvenal Silva Farias, Dayanne Lopes Gomes designed the experiments. Hugo Alexandre Oliveira Rocha, Kleber Juvenal Silva Farias, and Janaina Cristiana de Oliveira Crispim analyzed the data. Josélio Maria Galvão de Araújo, Wilmar Dias da Silva, Hugo Alexandre Oliveira Rocha, Eduardo Antônio Donadi, and Matheus de Freitas Fernandes-Pedrosa contributed with reagents, materials, and/or analysis tools. Emanuelly Bernardes-Oliveira and Dayanne Lopes Gomes contributed in manuscript preparation. Hugo Alexandre Oliveira Rocha and Janaina Cristiana de Oliveira Crispim refined the manuscript for publication. All authors read and approved the final manuscript.

\section{Acknowledgments}

The authors would like to thank Higher Education Personnel Improvement Coordination (CAPES) for the financial support of this research project (TOXINOLOGIA 2303800814/2011-83), Butantan Institute, National Council for Scientific and Technological Development-(CNPq), Ministry of Science, Technology, Innovation and Communications (MCTIC), Department of Biochemistry (UFRN) for allowing them to use the facilities of the cell culture room, and Institute of Tropical Medicine for the use of the FACSCantoll (UFRN). Hugo Rocha and Matheus Fernandes-Pedrosa are CNPq fellowship-honored researchers.

\section{References}

[1] B. Jacobs, A. Chetty, W. G. Horsnell, G. Schäfer, S. Prince, and K. A. Smith, "Hookworm exposure decreases human papillomavirus uptake and cervical cancer cell migration through systemic regulation of epithelial-mesenchymal transition marker expression," Scientific Reports, vol. 8, no. 1, 11547, 2018.

[2] B. Lachkar, T. Minaguchi, A. Akiyama et al., "Prognostic significance of PIK3CA mutation in stage IIB to IVA cervical cancers treated by concurrent chemoradiotherapy with weekly cisplatin," Medicine, vol. 97, no. 31, article no. ell392, 2018.

[3] V. Colpani, A. B. Bidinotto, M. Falavigna et al., "Prevalence of papillomavirus in Brazil: A systematic review protocol," $B M J$ Open, vol. 6, no. 11, article no. e011884, 2016.

[4] INCA, Instituto Nacional de Câncer José Alencar Gomes da Silva. Coordenação de Prevenção e Vigilância. Estimativa 2018: incidência de câncer no Brasil / Instituto Nacional de Câncer José Alencar Gomes da Silva, oordenação de Prevenção e Vigilância, Rio de Janeiro, Brazil, 2017.

[5] L. Pirtea, D. Grigoraş, P. Matusz et al., "Age and HPV type as risk factors for HPV persistence after loop excision in patients with high grade cervical lesions: an observational study," $B M C$ Surgery, vol. 16, no. 1, pp. 1-7, 2016.

[6] S. Rashid, S. Labani, and B. C. Das, "Knowledge, awareness and attitude on HPV, HPV vaccine and cervical cancer among the college students in India," PLOS ONE, vol. 11, no. 11, article no. e0166713, 2016.

[7] A. P. Ferreira-Costa, A. K. Gonçalves, P. R. L. Machado et al., "Immune response to human papillomavirus one year after prophylactic vaccination with AS04-adjuvanted HPV16/18 vaccine: HPV-specific IgG and IgA antibodies in the circulation and the cervix," Asian Pacific Journal of Cancer Prevention, vol. 19, no. 8, pp. 2313-2317, 2018.

[8] S. Mirbahari and M. Sadeghi, "The Prevalence of Genus Alpha Human Papillomavirus in Women with Uterine Cervical Infection and/or Inflammation in Western Iran," Materia Socio Medica Journal, vol. 30, no. 2, pp. 113-117, 2018.

[9] J. H. Joo, Y. S. Kim, and J.-H. Nam, "Prognostic significance of lymph node ratio in node-positive cervical cancer patients," Medicine, vol. 97, no. 30, article no. el1711, 2018.

[10] W. Ying, L. Liang, Y. Wang, and G. Qi, "Error analysis of applicator position for combined internal/external radiation therapy in cervical cancer," Oncology Letters, vol. 16, no. 3, pp. 3611-3613, 2018.

[11] G.-L. Fan, Y. Yao, L. Yao, and Y. Li, "PDCD5 transfection increases cisplatin sensitivity and decreases invasion in hepatic cancer cells," Oncology Letters, vol. 9, no. 1, pp. 411-417, 2015.

[12] L. Béchohra, F. Laraba-Djebari, and D. Hammoudi-Triki, "Cytotoxic activity of Androctonus australis hector venom and its toxic fractions on human lung cancer cell line," Journal of Venomous Animals and Toxins including Tropical Diseases, vol. 22, no. 1, article no. 29, 2016.

[13] H. S. Jang, S. R. Woo, K. Song et al., "API5 induces cisplatin resistance through FGFR signaling in human cancer cells," Experimental \& Molecular Medicine, vol. 49, no. 9, artilce no. e374, 2017.

[14] Y. Mei, C. Peng, Y.-B. Liu, J. Wang, and H.-H. Zhou, "Silencing RIF1 decreases cell growth, migration and increases cisplatin sensitivity of human cervical cancer cells," Oncotarget , vol. 8, no. 63, pp. 107044-107051, 2017.

[15] H. Guo, Z. Xiang, Y. Zhang, and D. Sun, "Inhibiting 6phosphogluconate dehydrogenase enhances chemotherapy efficacy in cervical cancer via AMPK-independent inhibition of RhoA and Racl," Clinical and Translational Oncology, vol. 21, no. 4, pp. 404-411, 2019.

[16] E. Bernardes-Oliveira, D. L. Gomes, G. M. Palomino et al., "Bothrops jararaca and bothrops erythromelas snake venoms promote cell cycle arrest and induce apoptosis via the mitochondrial depolarization of cervical cancer cells," EvidenceBased Complementary and Alternative Medicine, vol. 2016, Article ID 1574971, 9 pages, 2016. 
[17] B. Li, P. Lyu, X. Xi et al., "Triggering of cancer cell cycle arrest by a novel scorpion venom-derived peptide-Gonearrestide," Journal of Cellular and Molecular Medicine, vol. 22, no. 9, pp. 4460-4473, 2018.

[18] T. E. Heinen and A. B. Da Veiga, "Arthropod venoms and cancer," Toxicon, vol. 57, no. 4, pp. 497-511, 2011.

[19] E. Ortiz, G. B. Gurrola, E. F. Schwartz, and L. D. Possani, "Scorpion venom components as potential candidates for drug development," Toxicon, vol. 93, pp. 125-135, 2015.

[20] A. Gomes, P. Bhattacharjee, R. Mishra, A. K. Biswas, S. C. Dasgupta, and B. Giri, "Anticancer potential of animal venoms and toxins," Indian Journal of Experimental Biology, vol. 48, no. 2, pp. 93-103, 010.

[21] X.-Y. Zhang and P.-Y. Zhang, "Scorpion venoms in gastric cancer (Review)," Oncology Letters, vol. 12, no. 5, pp. 3683-3686, 2016.

[22] A. K. Al-Asmari, M. Islam, and A. M. Al-Zahrani, "In vitro analysis of the anticancer properties of scorpion venom in colorectal and breast cancer cell lines," Oncology Letters, vol. 11, no. 2, pp. 1256-1262, 2016.

[23] A. Díaz-García, J. L. Ruiz-Fuentes, H. Rodríguez-Sánchez, and J. A. R. F. Castro, "Rhopalurusjunceus scorpion venom induces apoptosis in the triple negative human breast cancer cell line MDA-MB-231," Journal of Venom Research, vol. 8, pp. 9-13, 2017.

[24] E. T. De Melo, A. B. Estrela, E. C. G. Santos et al., "Structural characterization of a novel peptide with antimicrobial activity from the venom gland of the scorpion Tityus stigmurus: Stigmurin," Peptides, vol. 68, pp. 3-10, 2015.

[25] D. L. Gomes, C. B. S. Telles, M. S. S. P. Costa et al., "Methanolic extracts from brown seaweeds Dictyota cilliolata and Dictyota menstrualis induce apoptosis in human cervical adenocarcinoma HeLa cells," Molecules, vol. 20, no. 4, pp. 6573-6591, 2015.

[26] C. M. Figueroa, M. Morales-Cruz, B. Suárez et al., "Induction of Cancer Cell Death by Hyaluronic Acid-Mediated Uptake of Cytochrome C," Journal of Nanomedicine \& Nanotechnology, vol. 6, no. 5, 2015.

[27] C. C. Liu, H. Yang, L. L. Zhang, Q. Zhang, B. Chen, and Y. Wang, "Biotoxinas para terapia de cancro," Jornal do Pacífico Asiático de Prevenção de Câncer, vol. 15, no. 12, pp. 4753-4758, 2014.

[28] A. Díaz-García, L. Morier-Díaz, Y. Frión-Herrera et al., "In vitro anticancer effect of venom from Cuban scorpion Rhopalurus junceus against a panel of human cancer cell lines," Journal of Venom Research, vol. 4, pp. 5-12., 2013.

[29] C. Luo, W. Fan, Y. Jiang, S. Zhou, and W. Cheng, "Glucoserelated protein 78 expression and its effects on cisplatinresistance in cervical cancer," Medical Science Monitor, vol. 24, pp. 2197-2209, 2018.

[30] J. M. Contreras-Ortiz, J. Vázquez-Chagoyán, J. MartínezCastañeda et al., "Resistance of cervical adenocarcinoma cells (HeLa) to venom from the scorpion Centruroides limpidus limpidus," Journal of Venomous Animals and Toxins including Tropical Diseases, vol. 19, no. 1, article 20, 2013.

[31] S. D. Gupta, A. Debnath, A. Saha et al., "Indian black scorpion (Heterometrus bengalensis Koch) venom induced antiproliferative and apoptogenic activity against human leukemic cell lines U937 and K562," Leukemia Research, vol. 31, no. 6, pp. 817-825, 2007.

[32] A. K. Al-Asmari, A. Riyasdeen, and M. Islam, "Scorpion venom causes apoptosis by increasing reactive oxygen species and cell cycle arrest in MDA-MB-231 and HCT-8 cancer cell lines," Journal of Evidence-Based Integrative Medicine, vol. 23, 2018. 


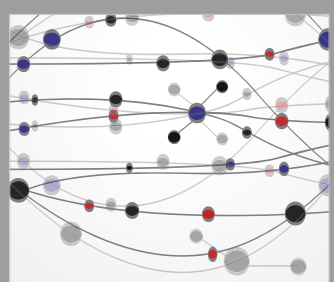

The Scientific World Journal
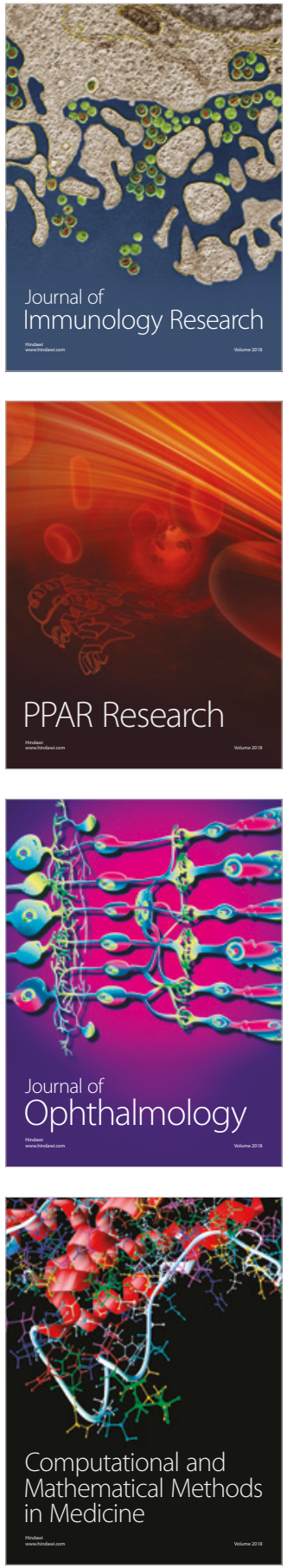

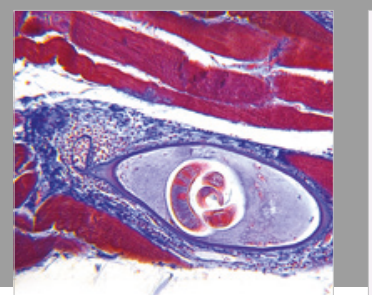

Gastroenterology Research and Practice

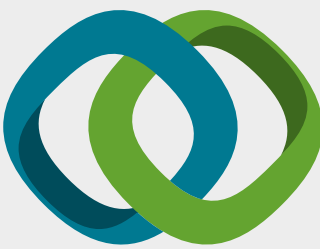

\section{Hindawi}

Submit your manuscripts at

www.hindawi.com
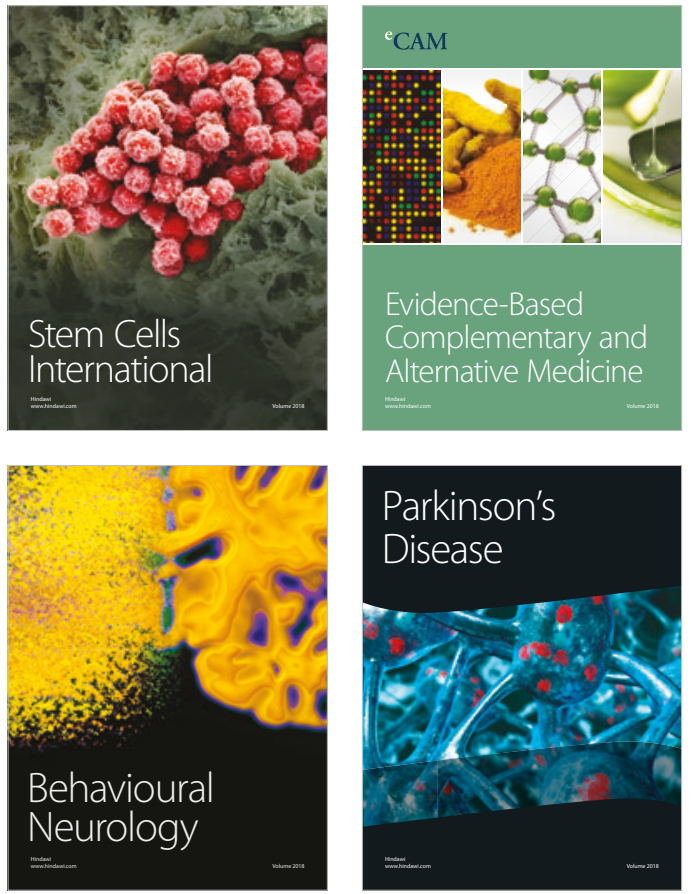

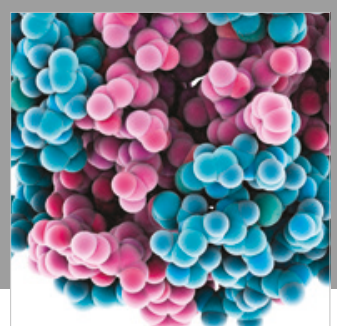

ournal of

Diabetes Research

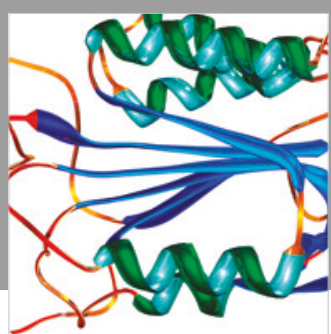

Disease Markers
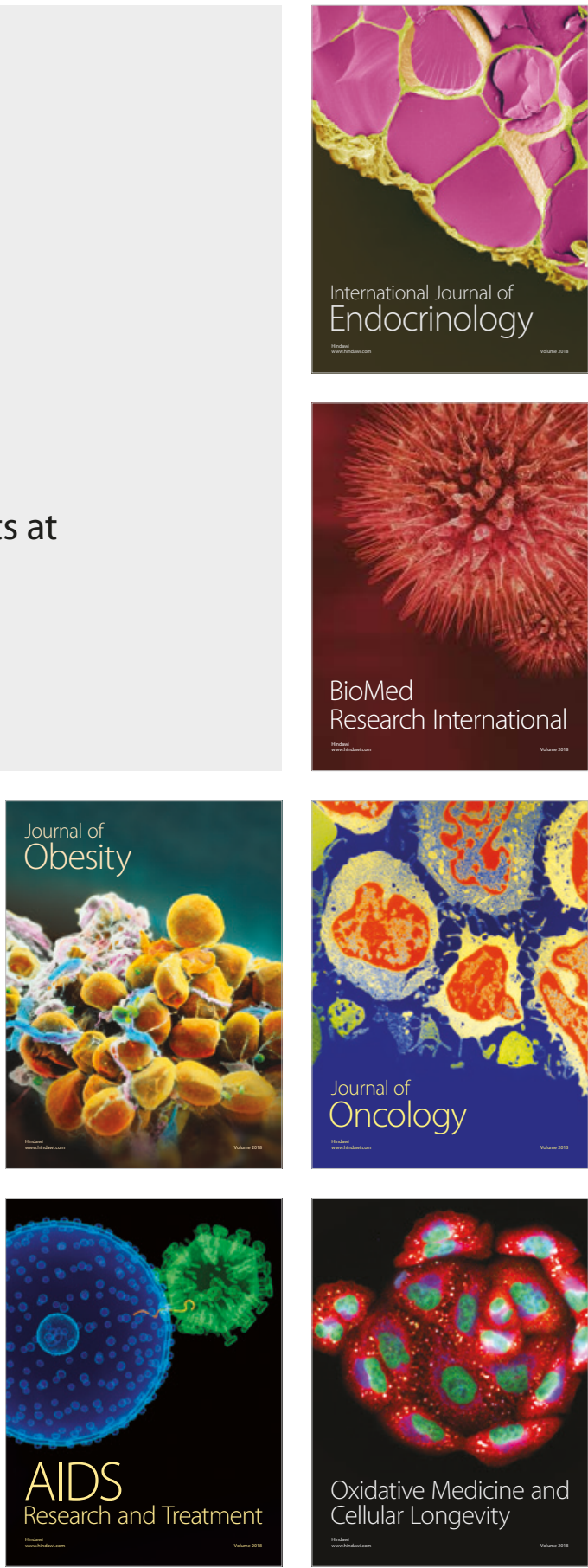